\title{
Potencial erosivo de doces azedos (sour candies) dissolvidos em água e saliva artificial
}

\section{Erosive potential of sour candies dissolved in water and artificial saliva}

Maria Mercês Aquino Gouveia Farias*

Ana Keila Soares ${ }^{* *}$

Brenda Bonvini***

Silvana Marchiori de Araújo ${ }^{* * * *}$

Beatriz Helena Eger Schmitt ${ }^{* * * *}$

\section{Resumo}

O consumo frequente de balas e doces ácidos está associado a etiologia da erosão dental. Objetivo: o objetivo deste estudo é mensurar o potencial erosivo de doces azedos (sour candies) dissolvidos em água e saliva artificial. Materiais e método: os doces Sour Tubes Ácido Fini ${ }^{\circ}$ sabores: maçã verde, tutti frutti, morango e melancia foram selecionados e divididos em 2 grupos - doces dissolvidos em água destilada (G-1) e doces dissolvidos em saliva artificial (G-2). O pH foi mensurado utilizando potenciômetro e eletrodo combinado de vidro, previamente calibrado com soluções padrão $\mathrm{pH}$ 7,0 e $\mathrm{pH}$ 4,0 antes de cada leitura. A acidez titulável foi mensurada adicionando-se alíquotas de $100 \mu \mathrm{L} \mathrm{NaOH}$ $1 \mathrm{M}$, até alcançar o $\mathrm{pH}$ 5,5. Os resultados foram submetidos à Análise de Variância (Anova), e as comparações das médias foram realizadas pelo teste Tukey, em um nível de $5 \%$ de significância $(p<0,05)$. Resultados: todas as balas apresentaram valores de $\mathrm{pH}$ abaixo de 5,5, quando dissolvidas em água (G-1) e saliva artificial (G-2). Na comparação entre os grupos, houve elevação significante do $\mathrm{pH}$ após dissolução em saliva artificial (G-2). A acidez titulável mostrou-se menor no grupo G-2. Conclusão: todos os doces ácidos dissolvidos em água e saliva artificial são potencialmente erosivos, podendo contribuir para a etiologia da erosão dental.

Palavras-chave: Erosão dentária. Doces. Saliva artificial. Concentração de íons de hidrogênio. Acidez.

\section{Introdução}

A erosão dental resulta da dissolução química dos tecidos dentários duros, provocada por ácidos de origem intrínseca (suco gástrico), extrínseca (dieta, medicamentos, gases ácidos e água de piscinas) e/ou substâncias quelantes (citrato) sem o envolvimento bacteriano $^{1,2}$. Sua etiologia multifatorial envolve a participação de fatores químicos, biológicos e comportamentais ${ }^{2,3}$.

A dieta representa o mais impactante fator de risco para erosão dental provocada por ácidos de origem extrínseca. Devido à prosperidade econômica, frutas e bebidas ácidas industrializadas tornaram-se amplamente consumidas e ofertadas. Atualmente, novos tipos de doces ácidos estão sendo desenvolvidos. Crianças são diariamente expostas a uma grande variedade de produtos ácidos disponíveis em supermercados, shoppings e cantinas escolares ${ }^{4}$.

Estudos recentes sobre prevalência da erosão dental em crianças e adolescentes incluíram que o consumo excessivo de balas e doces ácidos tem um potencial fator de risco $^{5-8}$.

Balas e doces azedos ou sour candies apresentam nas embalagens rótulos com termos como "ácido" ou "sour". A popularidade desse tipo de doce está relacionada ao sabor mais intenso e duradouro

Mestre em Odontopediatria, professora da Disciplina de Odontopediatria do Curso de Graduação em Odontologia da Universidade do Vale de Itajaí (Univali), Itajaí, SC, Brasil.

Graduada em Odontologia na Universidade do Vale de Itajaí (Univali), Itajaí, SC, Brasil.

* Graduada em Odontologia na Universidade do Vale de Itajaí (Univali), Itajaí, SC, Brasil.

${ }^{* * *}$ Doutora em Odontopediatria, professora da Disciplina de Odontopediatria do Curso de Graduação em Odontologia da Universidade do Vale de Itajaí (Univali), Itajaí, SC, Brasil.

***** Mestre em Odontopediatria, professora da Disciplina de Odontopediatria do Curso de Graduação em Odontologia da Universidade do Vale de Itajaí (Univali), Itajaí, SC, Brasil. 
que apresentam em relação ao sabor na versão original ${ }^{9}$.

Os fabricantes costumam usar uma combinação de diferentes tipos de ácidos (ascórbico, acético, adípico, cítrico, fumárico, lático e tartárico) na composição desses produtos, com a finalidade de alcançar a acidez desejada. Esses doces podem ser envoltos, recheados ou misturados a ácidos ${ }^{9,10}$.

Estudos apontam preocupação quanto ao consumo frequente, pois demonstram que esses ácidos são capazes de provocar erosão em dentes decíduos e permanentes ${ }^{9-11}$.

O potencial erosivo da dieta depende da participação de diversos fatores físico-químicos, tais como: tipo de ácido, pH, acidez titulável, potencial quelante, concentração de cálcio, fosfato flúor, temperatura e adesividade ${ }^{12,13}$. A saliva é o mais importante fator biológico envolvido na prevenção do desgaste erosivo por meio de suas propriedades, como: fluxo, capacidade tampão, ação de limpeza, potencial remineralizante, formação da película adquirida ${ }^{14-16}$.
No Brasil, são poucos os estudos sobre a erosividade de balas e doces e sua possível contribuição para o desenvolvimento da erosão dental. O conhecimento das propriedades bioquímicas dos alimentos, aliado ao efeito protetor da saliva, é uma importante ferramenta para a compreensão da dinâmica da erosão dental.

Este estudo objetivou mensurar o potencial erosivo de doces azedos ou sour candies dissolvidos em água e saliva artificial.

\section{Materiais e método}

Foram adquiridos em supermercados os produtos Sour Tubes Ácido Fini® nos sabores maçã verde, morango, tutti frutti e melancia (Quadro 1), constituindo 2 grupos:

- Grupo 1 (G-1): doces dissolvidos em água destilada

- Grupo 2 (G-2): doces dissolvidos em saliva artificial

Quadro 1 - Sabores selecionados e composição do produto segundo o fabricante

\begin{tabular}{|l|l|}
\hline \multicolumn{1}{|c|}{ Sabores } & \multicolumn{1}{c|}{ Composição } \\
\hline $\begin{array}{l}\text { SOUR TUBES ÁCIDO FINI } \\
\text { MAÇÃ VERDE }\end{array}$ & $\begin{array}{l}\text { Açúcar, xarope de glicose, farinha de trigo, amido modificado, água, gordura vegetal, sal, reguladores } \\
\text { de acidez: ácido málico e citrato trissódico. Acidulantes: ácido láctico e ácido cítrico. Gelificante: } \\
\text { gelatina. Aromatizante. Emulsificante: ésteres de mono e diglicerídios com ácidos graxos. Antioxidante: } \\
\text { lactato de sódio. Umectante: glicerina. Corante inorgânico: dióxido de titânio. Corantes artificiais: } \\
\text { tartrazina e azul brilhante FCF. Contém tartrazina. Contém glúten. }\end{array}$ \\
\hline $\begin{array}{l}\text { SOUR TUBES ÁCIDO FINI ® } \\
\text { MORANGO }\end{array}$ & $\begin{array}{l}\text { Açúcar, xarope de glicose, farinha de trigo, amido modificado, água, gordura vegetal, sal, reguladores } \\
\text { de acidez: ácido málico e citrato trissódico. Acidulantes: ácido láctico e ácido cítrico. Gelificante: } \\
\text { gelatina. Aromatizante. Emulsificante: ésteres de mono e diglicerídios com ácidos graxos. Antioxidante: } \\
\text { lactato de sódio. Umectante: glicerina. Corante inorgânico: dióxido de titânio. Corantes artificiais: } \\
\text { vermelho 40 e azorrubina. Contém glúten. }\end{array}$ \\
\hline $\begin{array}{l}\text { SOUR TUBES ÁCIDO FINI } \\
\text { TUTTI FRUTII }\end{array}$ & $\begin{array}{l}\text { Açúcar, xarope de glicose, farinha de trigo, amido modificado, água, gordura vegetal, sal, reguladores } \\
\text { de acidez: ácido málico e citrato trissódico. Acidulantes: ácido láctico e ácido cítrico. Gelificante: } \\
\text { gelatina. Aromatizante. Emulsificante: ésteres de mono e diglicerídios com ácidos graxos. Antioxidante: } \\
\text { lactato de sódio. Umectante: glicerina. Corante inorgânico: dióxido de titânio. Corante artificial: } \\
\text { azorrubina. Contém glúten. }\end{array}$ \\
\hline $\begin{array}{l}\text { SOUR TUBES ÁCIDO FINI } \\
\text { MELANCIA }\end{array}$ & $\begin{array}{l}\text { Açúcar, xarope de glicose, farinha de trigo, amido modificado, água, gordura vegetal, sal, reguladores } \\
\text { de acidez: ácido málico e citrato trissódico. Acidulantes: ácido láctico e ácido cítrico. Gelificante: } \\
\text { gelatina. Aromatizante. Emulsificante: ésteres de mono e diglicerídios com ácidos graxos. Antioxidante: } \\
\text { lactato de sódio. Umectante: glicerina. Corante inorgânico: dióxido de titânio. Corantes artificiais: } \\
\text { azorrubina, vermelho 40, tartrazina e azul brilhante FĆF. Contém tartrazina. Contém glúten. }\end{array}$ \\
\hline
\end{tabular}

Fonte: dados da pesquisa.

\section{Análise do pH e acidez titulável}

Para cada um dos sabores selecionados, foi necessário 1 embalagem de $80 \mathrm{~g}$. Os doces presentes em cada embalagem foram cortados e amassados com pistilo e gral de porcelana $305 \mathrm{~mL}$ (Nalgon Equipamentos Científicos, Itupeva, SP). Da massa resultante, pesaram-se 2 amostras de $20 \mathrm{~g}$ utilizando uma balança eletrônica analítica e de precisão (AE200S Mettler-Toledo Ind. e Com. Ltda. Alphaville, Barueri, SP, Brasil). Essas amostras de massa foram dissolvidas em $125 \mathrm{~mL}$ de água destilada (G1) e $125 \mathrm{~mL}$ de saliva artificial $\left(20 \mathrm{mM} \mathrm{NaHCO}_{3}\right.$,

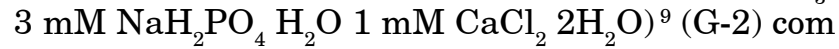

o auxílio de um bastão de vidro, até a obtenção de uma solução homogênea. A composição desta saliva artificial assemelha-se a composição inorgânica da saliva humana com a presença de tampões fosfato e bicarbonato. Obtiveram-se dessas soluções três amostras de $30 \mathrm{~mL}$ para cada um dos sabores presentes em cada grupo. Esse processo permitiu a leitura em triplicata do $\mathrm{pH}$ e da acidez titulável ${ }^{9}$.

$\mathrm{O} \mathrm{pH}$ foi mensurado sob temperatura ambiente e agitação constante (Agitador Magnético Fisaton), utilizando potenciômetro e eletrodo combinado de vidro (Tec-2, Tecnal Equipamentos para Laboratórios, Piracicaba, SP, Brasil) previamente calibrado 
com soluções padrão pH 7,0 e pH 4,0 antes de cada leitura.

Para a verificação da acidez titulável, adicionaram-se alíquotas de $100 \mu \mathrm{L} \mathrm{NaOH} \mathrm{1M,} \mathrm{sob} \mathrm{agitação}$ constante (Agitador Magnético Fisaton), até o pH alcançar 5,5. Esse procedimento foi realizado para cada um dos sabores.

Os resultados foram submetidos à Análise de Variância (Anova). As comparações das médias obtidas de $\mathrm{pH}$ foram realizadas pelo teste Tukey em um nível de $5 \%$ de significância $(\mathrm{p}<0,05)$.

\section{Resultados}

Todos os doces apresentaram valores de $\mathrm{pH}$ abaixo de 5,5, quando dissolvidos em água (G-1) e saliva artificial (G-2). Na comparação entre os grupos, houve elevação significativa do pH após dissolução em saliva artificial (G-2) (Tabela 1, Figura 1).

Tabela 1 - Médias e desvio padrão dos valores de $\mathrm{pH}$ após diluição em água $(G-1)$ e saliva artificial $(G-2)$

\begin{tabular}{l|c|c}
\hline \multicolumn{1}{c|}{ Sabores } & G-1 & G-2 \\
\hline Maçã verde & 2,86 a $\mathbf{B} \pm 0,06$ & 4,03 a $\mathbf{A} \pm 0,55$ \\
Morango & 2,95 a $\mathbf{B} \pm 0,10$ & 4,44 a $\mathbf{A} \pm 0,07$ \\
Tutti frutti & 2,59 a $\mathbf{B} \pm 0,33$ & 4,28 a $\mathbf{A} \pm 0,07$ \\
Melancia & 2,67 a $\mathbf{B} \pm 0,09$ & 4,06 a $\mathbf{A} \pm 0,09$ \\
\hline
\end{tabular}

Medias seguidas da mesma letra minúscula na vertical e maiúscula na horizontal não diferem significativamente entre si pelo teste de Tukey $(p<0,05)$.

Fonte: dados da pesquisa.
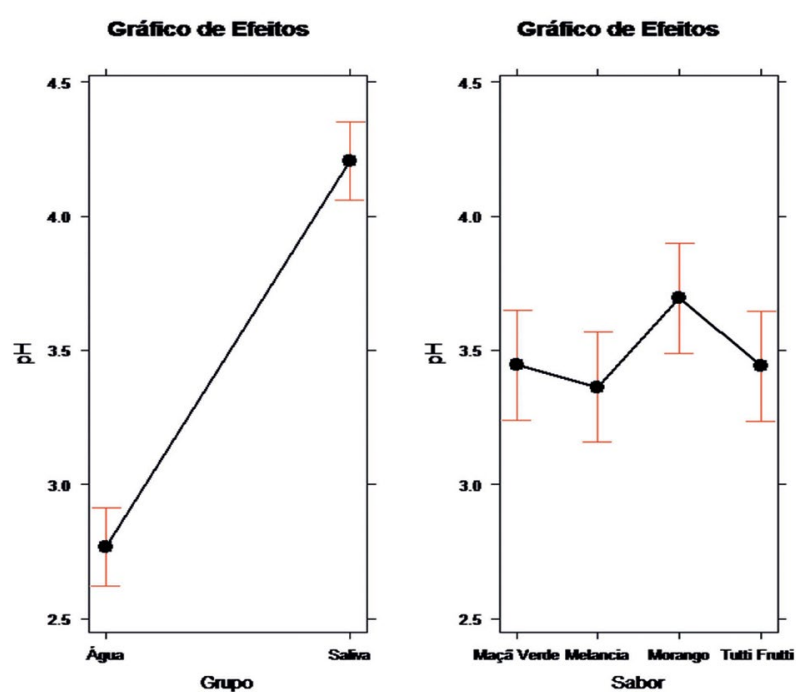

Figura 1 - Comportamento do pH observado pela média de todos os sabores e de cada sabor nos grupos (G-1 e G-2)

Fonte: dados da pesquisa.

A acidez titulável mostrou-se menor em G-2. Na comparação intragrupo, apresentou variação entre os sabores (Tabela 2).
Tabela 2 -Médias e desvio padrão dos valores de acidez titulável* após diluição em água (G-1) e saliva artificial (G-2)

\begin{tabular}{l|c|c}
\multicolumn{1}{c|}{ Sabores } & G-1 & G-2 \\
\hline Maçã verde & $733,33 \pm 57,4$ & $500,00 \pm 173,20$ \\
Morango & $633,33 \pm 57,74$ & $300,00 \pm 0,0$ \\
Tutti frutti & $833,33 \pm 57,74$ & $300,00 \pm 0,0$ \\
Melancia & $900,00 \pm 173,21$ & $600,00 \pm 100$ \\
\hline
\end{tabular}

* Volume $(\mu \mathrm{L})$ de $\mathrm{NaOH} 1 \mathrm{M}$ acrescido para elevar o $\mathrm{pH}$ para 5,5

Fonte: elaboração dos autores.

\section{Discussão}

A erosão dental proveniente de produtos ácidos caracteriza um novo desafio para a odontologia. Crianças estão cada vez mais expostas a uma grande variedade de produtos ácidos industrializados. $\mathrm{O}$ aparecimento de lesões erosivas em crianças que apresentam uma higiene adequada vem preocupado os cirurgiões-dentistas de todo o mundo ${ }^{10}$. Há grande variedade de doces ácidos e forte apelo comercial incentivando seu consumo ${ }^{4}$.

O potencial desmineralizante de balas e doces ácidos está descrito na literatura. Estudos demonstraram que as sour candies são capazes de provocar um desgaste erosivo maior e mais acentuado em dentes decíduos que os produtos de sabor original, quando comparado a dentes permanentes ${ }^{9,11}$.

No presente estudo, após diluição em água, todas os sabores apresentaram valores de $\mathrm{pH}$ inferiores a 5,5 , corroborando com os resultados de estudos prévios $^{11,17-23}$.

Os baixos valores de $\mathrm{pH}$ encontrados estão relacionados com a presença dos ácidos cítrico e lático na composição desses produtos. $\mathrm{O}$ pH é uma importante característica química de um produto, pois está ligado ao seu potencial desmineralizante. Potencial hidrogeniônico $(\mathrm{pH})$ é uma grandeza físico-química que permite indicar se um meio aquoso é ácido (valor inferior a 7) ou básico (valor superior a 7) ${ }^{12}$. Os ácidos fornecem ao meio íons de hidrogênio, $\mathrm{H}^{+}$, e/ou ânions quelantes, que provocam a desmineralização do tecido dentário duro. $\mathrm{O}$ íon $\mathrm{H}^{+}$se dissocia em água, atacando a superfície do cristal, dissolvendo-o ao se combinar com o íon carbonato ou fosfato, componentes da estrutura mineral dos dentes ${ }^{24}$.

Quando uma solução atinge o $\mathrm{pH}$ crítico, ela apresenta-se saturada em relação ao mineral dental. Porém, quando o pH está abaixo do crítico, a solução torna-se subsaturada em relação ao mineral dental e, portanto, capaz de desmineralizar a estrutura dentária ${ }^{16,25}$. Não há valores fixos para o pH crítico para a erosão do esmalte dental, pois este depende da presença de minerais na solução, especialmente cálcio. Soluções ácidas $(\mathrm{pH}<5,5)$ com cálcio na sua composição em concentrações maiores que as encontradas no fluido da placa $(3,5-8,2 \mathrm{mmol} / \mathrm{L})$ são 
consideradas supersaturadas em relação ao produto de solubilidade do esmalte e, portanto, incapazes de provocar erosão dental ${ }^{26}$; exceto quando o $\mathrm{pH}$ da solução for inferior a 3,9, como encontrado em todos os sabores do G-1 do presente estudo. Nesta situação, a solução é subsaturada em relação ao mineral dental, independentemente da presença de íons cálcio, fosfato e flúor na sua composição, que apenas podem modular a velocidade da dissolução ${ }^{26}$.

A diluição em saliva artificial (G-2) provocou elevação significativa do $\mathrm{pH}$, resultado semelhante ao de estudos anteriores ${ }^{9,18,19}$.

Além de pH, a acidez titulável também auxilia na predição do potencial erosivo de um produto. Refere-se à concentração total de todos os tipos de ácidos que se dissociam para fornecer íons $\mathrm{H}+$ entre os valores de $\mathrm{pH}$ inicial e final ${ }^{13}$. Ela mensura a concentração de ácido não dissociado presente em alimentos e bebidas não detectados durante a mensuração do $\mathrm{pH}$, que detecta apenas os íons $\mathrm{H}+$ livres na solução. No ambiente bucal, quanto mais elevada a acidez titulável, maior o tempo necessário para a saliva neutralizar o ácido, prolongando o potencial desmineralizante do produto ${ }^{3}$. Isto justifica o fato de alguns produtos com $\mathrm{pH}$ semelhante apresentarem potencial erosivo distintos. Isto depende da quantidade de ácido não dissociado na solução. Quanto menor o pH e mais elevada a acidez titulável, maior é o potencial erosivo do produto.

Nossos resultados demonstraram que os doces dissolvidos em água e saliva artificial apresentaram variada acidez titulável, com redução significante do volume de $\mathrm{NaOH} 1 \mathrm{M}$ para alcançar pH 5,5 após diluição na saliva artificial, fato também observado em diversos estudos ${ }^{9,18,19}$.

Em todos os produtos analisados neste estudo, os ácidos láctico e cítrico estão presentes na composição segundo o fabricante. Mas, ao se observar as variações de acidez titulável, sugere-se que há variações nas concentrações destes ácidos nos diferentes sabores. Desconhece-se também a proporção de cada tipo de ácido na composição dos distintos sabores. A acidez titulável reflete a presença de ácido não dissociado na solução, e os diferentes tipos de ácido apresentam constantes de dissociação distintas, dissociando-se na dependência do $\mathrm{pH}$ do meio ${ }^{13}$. Todos os ácidos fracos como o cítrico e o láctico, presentes nestes produtos, dissociam-se progressivamente com a elevação do $\mathrm{pH}^{13}$. Essas condições podem contribuir para as variações observadas na acidez titulável.

$\mathrm{Na}$ medida em que o pH se altera, a quantidade de ácido dissociado, fornecendo íons $\mathrm{H}+$ para o meio, também se altera, influenciando a acidez titulável. Também não sabemos qual ácido predomina em cada produto e qual a contribuição isolada de cada um na acidez titulável para alcançar pH 5,5. Sabe-se, por exemplo, que o ácido cítrico se dissocia numa faixa de $\mathrm{pH}$ entre 3,13 e 6,42.

Observou-se, no presente estudo, que a saliva artificial elevou o $\mathrm{pH}$ e reduziu a acidez titulável das sour candies, alterando seu potencial erosivo. Essas mudanças de comportamento das soluções são atribuídas à capacidade da saliva artificial de diluir e tamponar os ácidos presentes na solução, pois, assim como a saliva humana, apresenta em sua composição tampões de fosfato e bicarbonato.

A ação da saliva sobre a erosividade das balas é relatada na literatura. Pesquisas in vivo revelaram aumento de fluxo e queda do $\mathrm{pH}$ salivar para valores abaixo de 5,5 durante o consumo de balas ácidas e o retorno aos valores normais cerca de 1 a 2 minutos após cessado o consumo ${ }^{17,27}$. Esses dados revelam que, durante o consumo de balas ácidas, há a permanência de um meio ácido na cavidade bucal, proporcionando condições para o desgaste erosivo. Outro aspecto que deve ser observado é que, no padrão de consumo de balas e doces, observa-se exposição prolongada dos dentes aos ácidos contidos nos produtos, por serem consumidos mais lentamente que outros produtos ácidos industrializados. Esses aspectos podem contribuir para a sobreposição da capacidade protetora da saliva durante sua ingestão $0^{17,27,28}$.

Os resultados obtidos neste estudo demonstraram que, embora a saliva exerça um efeito protetor contra a erosão dental, neste modelo de estudo, esta proteção foi parcial, assim como observado em estudos prévios ${ }^{9,18,19}$.

A extrapolação dos nossos resultados é limitada, visto que a dinâmica da atuação salivar no meio bucal é mais complexa, não comtemplada em estudos in vitro. Contudo, podemos inferir que os produtos analisados apresentam potencial para contribuir para etiologia da erosão dental.

O reconhecimento dos fatores de risco é essencial para o gerenciamento da erosão dental ${ }^{16}$. Algumas medidas devem ser adotadas para reduzir os danos provocados pelo consumo de sour candies: não sugá-las; não mascá-las por longos períodos de tempo; lavar a boca com água imediatamente após seu consumo; estimular o fluxo salivar por meio do consumo de gomas de mascar sem açúcar; aguardar cerca de 30 minutos a 1 hora para escovar os dentes; usar cremes dentais fluoretados, com baixa abrasividade e com compostos que protegem a estrutura do esmalte ${ }^{10}$.

\section{Conclusão}

Todos os doces ácidos dissolvidos em água ou saliva artificial são potencialmente erosivos e podem contribuir para a etiologia da erosão dental.

\section{Agradecimentos}

Ao Programa de Iniciação Científica Artigo 170, Governo do Estado de Santa Catarina, Pró-Reitoria de Pesquisa, Pós-Graduação, Extensão e Cultura da Universidade do Vale do Itajaí, que financiou a pesquisa. 


\section{Abstract}

The frequent consumption of sour candies is associated with the etiology of dental erosion. Objective: to measure the erosive potential of sour candies dissolved in water and artificial saliva. Methods: the Sour Tubes Ácido Fini ${ }^{T M}$ candies of the flavors green apple, tutti frutti, strawberry, and watermelon were select and grouped into 2 groups: candies dissolved in distilled water (G1) and candies dissolved in artificial saliva (G-2). The $\mathrm{pH}$ was measured using a potentiometer and combined glass electrode previously calibrated with standard $\mathrm{pH}$ 7.0 and $\mathrm{pH} 4.0$ solutions before each reading. Titratable acidity was measured by adding aliquots of $100 \mathrm{uL}$ $1 \mathrm{M} \mathrm{NaOH}$ up to $\mathrm{pH}$ 5.5. The results were subjected to Analysis of Variance (ANOVA) and the means were compared with Tukey's test at 5\% significance level $(p<0.05)$. Results: all candies showed $\mathrm{pH}$ values below 5.5 when dissolved in water $(G-1)$ and artificial saliva $(G-2)$. In the comparison between groups, there was a significant $\mathrm{pH}$ increase after the dissolution in artificial saliva (G-2). The titratable acidity was lower for G-2. Conclusion: all sour candies dissolved in water and artificial saliva are potentially erosive and may contribute to the etiology of dental erosion.

Keywords: Dental erosion. Candies. Artificial saliva. Hydrogen ion concentration. Acidity.

\section{Referências}

1. Gans C. Definition of erosion and links to tooth wear. Monogr Oral Sci 2006; 20:9-16.

2. Magalhães AC, Rios D, Honorio HM, Buzalaf MAR. Insights into preventive measures for dental erosion. J Appl Oral Sci $2009 ; 17(2): 75-86$.

3. Lussi A, Schlueter N, Rakhmatullina E, Ganss C. Dental erosion-An overview with emphasis on chemical and hispopatholigicol aspects. Caries Res 2011; 45(1 Suppl):2-12.

4. Gambon DL, Brand HS, Veerman ECI, Dental erosion in the 21st century: what is happening to nutritional habits and lifestyle in our society? Br Dent J 2012; 213(2):55-7.

5. Correa MSNP, Corrêa FNP, Correa JPNP, Murakami C, Mendes FM. Prevalence and associated factors of dental erosion in children and adolescents of a private dental practice. Int J Paediatr Dent 2011; 21(6):451-8.

6. Farias MMAG, Silveira EG, Schmitt BHE, Araújo SM, Baier IBA. Prevalência da erosão dental em crianças e adolescentes brasileiros. Salusvita 2013; 32(2):187-98.

7. Salas MM, Nascimento GG, Vargas-Ferreira F, Huysmans MC, Demarco FF. Diet influenced tooth erosion prevalence in children and adolescents: results of a meta-analysis and meta-regression. J Dent 2015; 43(8):865-75.

8. Søvik JB, Skudutyte-Rysstad R, Tveit AB, Sandvik L, Mulic A. Sour sweets and acidic beverage consumption are risk indicators for dental erosion. Caries Res 2015; 49(3):243-50.

9. Wagoner SN, Marshall TA, Quian F, Wefel JS. In vitro enamel erosion associated with commercially available original and sour candies. J Am Dent Assoc 2009; 140(7):906-13.

10. Feltham EB. The power of sour candies: a dental hygienist's battle against dietary dental erosion. CDHA Journal 2010; 25(1):16-18. Disponível em: <http://ww1.prweb.com/prfiles/2010/10/26/2304804/CDHAJournalSourCandy110.pdf>. Acesso em: 18 fev 2017.
11. Davies R. Summary of: sour sweets: a new type of erosive challenge. Br Dent J 2008; 204(2); 84-85.

12. Furtado JR, Freire VC, Messias DCF, Turssi CP. Aspectos físico-químicos relacionados ao potencial erosivo de bebidas ácidas. RFO UPF 2010; 15(3):325-30.

13. Shellis RP, Featherstone JDB, Lussi A. Erosive tooth wear. Understanding the chemistry of dental erosion. Monogr Oral Sci 2014; 25:163-79.

14. Buzalaf MA, Hanna AR, Kato MT. Saliva e dental erosion. J Appl Oral Sci 2012; 20(5):493-502.

15. Hara AT, Zero DT. Erosive tooth wear the potential of saliva in protecting against dental erosion. Monogr Oral Sci 2014; 25:197-205.

16. West NX, Joiner A. Enamel mineral loss. J Dent 2014: 4 Suppl 1: S2-S11.

17. Brand HS, Gambon DL, Paap A, Bulthuis MS, Veerman EC, Amerongen AV. The erosive potential of lollipops. Int Dent $J$ 2009; 59(6):358-62.

18. Bonvini B, Soares AK, Farias MMAG, Araújo SM, Schmitt BHE. Mensuração do potencial erosivo de balas dissolvidas em água e saliva artificial. Rev Odontol Unesp 2016; 45(3):154-8.

19. Farias MMAG, Oliveira MML, Schmitt BHE, Silveira EG, Araujo SM. Brazillian journal of oral sciences 2016; 15(1):75-8.

20. Farias MMAG, Ramos BLM, Silveira EG. Avaliação do potencial erosivo de balas duras. Robrac 2016; 25(74):135-8.

21. Ganbom DL, Brand HS, Nieuw Amerogen AV. The erosive potential of candy spray. Br Dent J 2009; 206(10):E20.

22. Lazzaris M, Farias MMAG, Araújo SM, Schmitt BEH, Silveira EG. Erosive potential of commercially available candies. Pesqui Bras Odontopediatria Clin Integr 2015; 15(1):7-12.

23. Silva JG, Farias MMAG, Silveira EG, Araújo SM, Schmitt BHE. Evaluation of the erosive potential of acidic candies consumed by children and tennagers. Journal of Pharmacy and Nutrition Sciences 2013; 3:262-5. Disponível em: $<$ http://www.lifescienceglobal.com/pms/index.php/jpans/article/view/1272>. Acesso em: 10 Dec 2014.

24. Featherstone JDB, Lussi A. Understanding the chemistry of dental erosion. Monogr Oral Sci 2006; 20:66-76.

25. Dawes C. What is the critical pH and why does a tooth dissolve in acid? J Can Dent Assoc 2003; 69(11):722-4.

26. Lussi, A; Carvalho, T. S. Erosive tooth wear. A multifactorial condition of growing concern and increasing knowledge. Monogr Oral Sci 2014; 25:1-25.

27. Brand HS, Gambon DL, Van Dop LF, Van Liere LE, Veerman EC. The erosive potential of jawbreakers. Int J Dent Hyg 2010; 8(4):308-12.

28. Gambon DL, Brand HS, Amerongen AVN. Acidic candies affect saliva secretion rates and oral fluid acidity. Ned Tijdschr Tandheelkd 2007; 114(8):330-4.

\section{Endereço para correspondência:}

Maria Mercês Aquino Gouveia Farias Rua Bartolomeu de Gusmão, 209, Carianos 88047-520, Florianópolis, SC, Brasil Telefones: (048) 3207-6006 ou (048) 99622-1645 E-mails: mercesfarias@gmail.com mercesfarias@univali.br

Recebido: 29/06/2017. Aceito: 31/07/2017. 